\title{
Times Are Changing
}

Andrea Wendling, MD

(Fam Med. 2018;50(9):657-8.)

doi: 10.22454/FamMed.2018.231112

When you cease to exist, then who will you blame?

-Bob Dylan ${ }^{1}$

I became a family doctor for a basic reason-fundamentally, I wanted to care for a community. Finding a community that needed a doctor, and then working to meet the needs of that community as best I could-for a lifetime-was simply and exactly what I was put together to do. As passionately as other students dreamed of being in the operating room or curing HIV, I could picture that community waiting for me, full of people with their own struggles, joys, and undiscovered issues. I knew I would fall in love with that place when I found it, and because of this I needed to be trained in a way that I could become what they needed. This was always family medicine. I was always a family doctor.

I'm now 25 years from that decision. I found my community, and together with my partners we've done our best to meet the needs of the people we care for. We don't use every skill that we learned in residency, but in our rural community we do a lot. Like most family doctors, we've occasionally run up against systembased issues like privileging or contracting, but we've worked through these and have felt like we've been able to maintain our autonomy and professional integrity. We have felt valued by our health system, our colleagues, and our community.

Even in our community though, things are changing. As our hospital and the hospitals nearby have been acquired by larger health systems, our role has subtly begun to shift. Almost imperceptibly, our value within the community is feeling less important than our value to the health system, which has a strikingly different agenda. The rules have changed, and our specialty's flexibility is being leveraged against us. As health systems have realized

the value of providing ambulatory primary care for a population, we are increasingly relegated to that role. As this happens within our health systems, it is happening to our communities, and it is happening within our residencies. Our profession is selling its generalist soul to become the specialty of ambulatory care, in exchange for nothing more than a contemporary seat at the table.

As our value as family physicians shifts conceptually from our role within the community to our role within the health system, our mindset inevitably shifts from service to production. Our value, which historically was defined by patient choices, outcomes, and services, shifts to the currency of business-charges, value units, and market share. This is unfortunate, as we are respected within our communities because of our service, not because of our business success. And as our accountability drifts toward our health systems, what we may be risking is the respect of our patients.

Defining ourselves based on our current value to the health system is also inherently dangerous because ultimately, we are not cheap. Although communities and patients may value the ability to receive care from a well-trained physician, health systems have realized that ambulatory primary care services can be distributed throughout our communities in many ways, almost all of which are less expensive than a physician-driven model. As we allow our specialty to be defined predominantly by ambulatory adult medicine services, we also risk inviting a path to our own extinction.

Our utmost value is still the fact that we as family physicians can provide the basic health care services that a community needs-all of them. That is why this issue's lead article is so important. Dr Goldstein and her coauthors approach the issue of supporting family physicians who provide maternity care from a community-responsiveness perspective. They begin by looking within our professional communities 
to identify challenges, then highlight solutions informed by experience. They suggest that to address challenges, family physicians might develop practice communities, identify and address professional needs, and determine unique niches they could fill locally such as maternity care for teens, comprehensive care for women struggling with opiate and other drug addiction, or providing vaginal birth after cesarean section (VBAC) options within areas where this service has been limited. All while continuing to highlight the unique strength of our family medicine maternity care modelcomprehensive, longitudinal, and family-centered care for both mothers and infants.

The excellent solutions they present call upon the tenets of our specialty, which include continuing, comprehensive health care that integrates biological, clinical, and behavioral sciences, and a scope of care that encompasses all ages and all organ systems and diseases. ${ }^{2,3}$ To address the needs of a community in these ways, a family physician might simultaneously address the addiction issues of a teenage mom, assess whether a vaginal delivery is safe within the parameters of a current viral load, and treat newborn opiate withdrawal. Yes, this is complex and will most likely require a support team. But arguably, because of our breadth of training, a family physician is the ideal care provider to lead that team.

Not every family physician needs to provide all care. But all family physicians should be trained to provide the basic care that every community needs, and from that point of comprehensiveness, should then discover the needs of their own communities. Starting instead from the perspective of the health system-defining our base training by what is most convenient, most cost effective, or most practical for a specific community rather than by advocating for the core of our specialty-is allowing ourselves to be precariously redefined.

Health systems must be successful to maintain viability. But closing mental health inpatient units, choosing not to provide comprehensive maternity services such as trial of labor after cesarean sections to entire populations of rural women, and duplicating existing services in our wealthiest communities rather than expanding to persistently underserved areas is not the way to do it. Our responsibility, along with that of our board and society leadership, is to advocate against decisions like this that harm the health of our communities.

As for-profit and not-for-profit health systems grow, major decisions and profits are diverted centrally, away from our communities and often with little local representation or economic return. Similarly, these health systems are absorbing and creating residency programs, which are then under the same pressures as clinicians. As health systems gain more power over education, the risk is that the priorities of our residency directors and academic leaders will shift away from serving our profession and toward creating business models most likely to increase profits for these employers. We must continue to define our profession, our training, and our capacity for service based on the tenets of our profession. And we need to own this definition.

As educators, we are the front line. We are modeling the behavior that our residents will reflect. We need to change our language and continue to define our worth based on what we can offer to communities, looking to fill the roles that are most responsive to needs. The shift to value-based health care is here, but it too is evolving. As a specialty, we need to build this system of health care for all of our communities in the way that we know it should exist.

CORRESPONDENCE: Address correspondence to Dr Andrea Wendling, Michigan State University, Department of Family Medicine, $223 \mathrm{~N}$ Park St, Boyne City, MI 49712. 231-582-5314. wendli14@msu.edu.

\section{References}

1. Dylan B. Angelina. The Bootleg Series, Vol 1-3: Rare \& Unreleased 1961-1991 [CD]. New York: Columbia Records; 1991.

2. American Academy of Family Physicians. Definition of Family Medicine. https://www.aafp.org/about/policies/all/familymedicine-definition.html. Accessed August 18, 2018.

3. American Board of Family Medicine. Definitions and Policies. https://www.theabfm.org/about/policy.aspx. Accessed August 18,2018 .

\section{Editor's Note}

The September 10, 2018 issue of the Journal of the American Board of Family Medicine includes a paper we believe to be important to our readers. The paper comments on the growing problem of predatory medical journals and its impact on authors and readers. We encourage our readers to read this paper and to discuss it with their colleagues.

Bowman MA, Saultz JW, Phillips WR. Beware of predatory journals: a caution from editors of three family medicine journals. J Am Board Fam Med. 2018; 31(5):671-676. doi: 10.3122/jabfm.2018.05.180197. 